\title{
BMJ
}

\section{Portrayal of caesarean section in Brazilian women's magazines: 20 year review}

\author{
Maria Regina Torloni, medical doctor, ${ }^{1,2}$ Silvia Daher, medical doctor, ${ }^{2}$ Ana Pilar Betrán, medical officer, ${ }^{3}$ \\ Mariana Widmer, technical officer, ${ }^{3}$ Pilar Montilla, technical officer, ${ }^{4}$ Joao Paulo Souza, medical officer, ${ }^{3}$ Mario \\ Merialdi, unit coordinator ${ }^{3}$
}

Brazilian Cochrane Centre, Rua Pedro de Toledo 598, São Paulo, Brazil, CEP 04039-001

${ }^{2}$ Department of Obstetrics, São Paulo Federal University, Rua Napoleão de Barros 875, São Paulo, CEP 040024-002

${ }^{3}$ Department of Reproductive Health and Research, World Health Organization, Geneva, Switzerland

${ }^{4}$ Osservatorio Nazionale sulla salute della Donna (O.N.Da), Milan, Italy

Correspondence to: M Torloni ginecologia@terra.com.br

Cite this as: $B M J$ J 2011;342:d276 doi:10.1136/bmj.d276

\section{ABSTRACT}

Objective To assess the quality and comprehensiveness of the information on caesarean section provided in Brazilian women's magazines.

Design Review of articles published during 1988-2008 in top selling women's magazines.

Setting Brazil, one of the countries with the highest caesarean section rates in the world.

Data sources Women's magazines with the largest distribution during the study period, identified through the official national media indexing organisations.

Selection criteria Articles with objective scientific information or advice, comments, opinions, or the experience of ordinary women or celebrities on delivery by caesarean section.

Main outcome measures Sources of information mentioned by the author of the article, the accuracy and completeness of data presented on caesarean section, and alleged reasons why women would prefer to deliver though caesarean section.

Results 118 articles were included. The main cited sources of information were health professionals $(78 \%$ $(n=92)$ of the articles). $71 \%(n=84)$ of the articles reported at least one benefit of caesarean section, and $82 \%(n=97)$ reported at least one short term maternal risk of caesarean section. The benefits most often attributed to delivery by caesarean section were reduction of pain and convenience for family or health professionals. The most frequently reported short term maternal risks of caesarean section were increased time to recover and that it is a less natural way of giving birth. Only one third of the articles mentioned any long term maternal risks or perinatal complications associated with caesarean section. Fear of pain was the main reported reason why women would prefer to deliver by caesarean section.

Conclusions Most of the articles published in Brazilian women's magazines do not use optimal sources of information. The portrayal of caesarean section is mostly balanced, not explicitly in favour of one or another route of delivery, but incomplete and may be leading women to underestimate the maternal/perinatal risks associated with this route of delivery.

\section{INTRODUCTION}

A caesarean section is a surgical procedure that was developed to prevent or treat life threatening maternal or fetal complications. The proportion of births using caesarean delivery has been steadily increasing in most high income and middle income countries, despite the lack of sound scientific evidence indicating any substantial maternal or perinatal benefits from increasing rates of caesarean section and consistent reports of increased risks for the mother and baby. ${ }^{1-5}$ In many developed nations and in Latin America, approximately a third of all deliveries occur by caesarean section. ${ }^{6}$ In the past few decades, Brazil has been one of the countries with highest proportion of deliveries by caesarean section in the world. ${ }^{26}$ According to data from a national health survey, the overall caesarean section rate in Brazil in 2006 was $43.6 \%,{ }^{7}$ but in the private sector it can be more than $80 \% .^{8}$ More than 850000 unnecessary caesarean sections are being done each year in Latin America, and almost half of them occur in Brazil. ${ }^{2}$

Despite worldwide concern, debate, and research on this subject, the modifiable causes of rising caesarean section rates remain unclear. Without a better understanding of the possible causes and contributing factors for this tendency, developing and implementing effective strategies to help curb this upward trend and reduce the number of unnecessary caesarean sections will be difficult. This is important, as high rates of nonmedically indicated caesarean section have financial implications and unnecessarily expose mothers and children to risks and consequences that are not yet fully understood.

Contemporary women are exposed to and have access to a wide range of information on health topics, including their options for childbirth. This exposure can influence their opinions and affect the decision making process. ${ }^{9-11}$ Additionally, women's views and preferences on type of delivery are, for different reasons, being increasingly respected by practising obstetricians. ${ }^{1213}$ Women's magazines are one of the most ubiquitous sources of information and can play a critical role in shaping women's opinions and influencing the decisions they make. ${ }^{9}$ However, to the best 
of our knowledge, the accuracy and comprehensiveness of the information on caesarean section compared with vaginal delivery presented in these magazines has not been evaluated.

In this context, we set out to review the top selling women's magazines published in the past 20 years in Brazil, one of the countries with the highest rates of caesarean section in the world, to analyse the content of the articles that presented information or expressed views related to caesarean section. This is part of a larger worldwide multi-country investigation covering women's magazines from countries in Europe, Latin America, and North America, where caesarean section rates are increasing in an unprecedented manner. Our hypothesis was that the information transmitted to women through this media was incomplete, biased in favour of caesarean section (possibly presenting it as a more beneficial route of delivery), or both.

The specific objectives of the review were to assess the sources of information that the magazine authors reported to have consulted for writing their articles; the accuracy and comprehensiveness of the information presented on caesarean section versus vaginal delivery; and the views, opinions, or preferences of ordinary women and celebrities about route of delivery and the alleged reasons or motives why they would prefer a caesarean section to a vaginal delivery.

\section{METHODS}

\section{Search strategy}

We searched for articles published in women's magazines with the largest circulation in Brazil from January 1988 to December 2008. The selection of magazines was derived from the national media indexing yearbook, ${ }^{14}$ the institute of circulation, ${ }^{15}$ and the national association of magazine editors, ${ }^{16}$ which report on the annual circulation of all national

\section{Content analysis form: summary}

\section{Size and format of article}

2. Author's credentials

3. Sources of information

4. Information on women's experiences reported

5. Completeness of information on caesarean section:

- Statistics on caesarean section (prevalence)

- WHO recommendations on caesarean section rate

- Indications for caesarean section

- Need for and effect of anaesthesia

- Duration of hospital stay

- General maternal and perinatal risks

- Medical costs

6. Risks and benefits of caesarean section:

- Maternal (short term and long term)

- Perinatal

7. Reasons for preferring elective or intrapartum caesarean section

8. Opinion of celebrities on route of delivery magazines categorised according to their types. On the basis of these sources, we identified and selected the women's magazines with the largest distribution (up to approximately 10 magazines a year) for each of the 20 years of the study period (list available from corresponding author). A journalist experienced in health related subjects retrieved all the issues of these top selling women's magazines for each of these 20 years and hand searched them at the archives of the publishing houses or public libraries. This journalist was trained in the study methods and received supervision throughout the process. This collaborator photocopied all articles that had any information on women's health, pregnancy, or childbirth, and two investigators (MRT and SD), both Brazilian medical doctors with extensive training in obstetrics and public health, independently assessed the full texts for possible inclusion.

\section{Inclusion and exclusion criteria}

We selected all articles that mentioned information on caesarean section for full text reading and data extraction. This included articles that presented any form of objective, scientific information or advice from health professionals, as well as articles that presented the experiences, comments, views, or opinions of ordinary women, celebrities, or journalists regarding childbirth by caesarean section. We excluded articles that just mentioned someone giving birth by caesarean section but without any additional information, comment, or judgment as to the route of delivery. We also excluded articles that reported on the use of caesarean section exclusively for high risk or selected populations (for example, teenagers, women aged over 40 , HIV positive patients, or those with other specific obstetric or clinical conditions such as twin pregnancies, preterm birth, fetal malformations, or cardiac, renal, pulmonary, or other disease).

\section{Data extraction process}

We used a content analysis abstraction form especially designed for this review to extract key information (box). The content analysis form was designed by a panel of experts that included obstetricians, epidemiologists, and professionals experienced in qualitative research and public health. The form was designed on the basis of a series of items discussed by Oxman et al to critically appraise health reports in the lay press. $^{17}$

The form was designed to retrieve information on various specific aspects such as potential short term and long term maternal and perinatal benefits and risks of caesarean section compared with vaginal delivery; reasons why women or doctors would prefer a caesarean section; and the opinion, views, or preferences of ordinary women and potential role models on route of delivery. We compiled a list of potential short term and long term maternal and perinatal benefits and risks associated with caesarean section from authoritative medical sources for use in the content analysis form. ${ }^{18-21}$ This form also assessed the sources for any medical or 
scientific information presented in each article, such as the type and expertise of health professionals, medical journals, hospitals, universities, the World Health Organization, or other organisations.

We used the first 10 included articles to test the content extraction forms, which were discussed and modified until consensus was reached and the method for data extraction was standardised. Two independent reviewers (MRT and SD) read and extracted the next 30 included articles in duplicate and compared the results to determine the inter-observer agreement. Differences were discussed until consensus was reached. The same two reviewers read and extracted all subsequent articles individually. We downloaded data from the content extraction forms into Microsoft Excel and analysed them.

\section{RESULTS}

A list of the top selling Brazilian women's magazines for each of the years included in this review is available from the authors on request. The circulation of the eligible magazines ranged from 10000 to 506000 copies a month. During the 20 year period, we retrieved 13 different women's magazines; as most of these magazines had monthly issues, we hand searched a total of 2868 different issues. Of these, 325 (11.3\%) issues carried articles on pregnancy and childbirth that were considered potentially relevant and photocopied for analysis. After reading of the full text, 118 articles presented in separate issues fulfilled the selection criteria and were included in this study. The included articles, with specific information on caesarean section, represented $4.1 \%$ of all the issues published in Brazilian women's magazines from 1988 to 2008 and $36 \%$ of all the articles on pregnancy and childbirth. All articles were written by Brazilian authors.

Table 1| Main characteristics and sources of information for articles on caesarean section published in Brazilian women's magazines, 1988-2008. Values are numbers (percentages) unless stated otherwise

\begin{tabular}{lc}
\hline Main focus of article & Articles (n=118) \\
\hline General information on pregnancy/delivery & $93(79)$ \\
\hline Personal account of pregnancy/delivery & $51(43)$ \\
\hline Medical topic & $8(7)$ \\
\hline Social topic & $2(2)$ \\
\hline Size and type of article & $4(2.1)$ \\
\hline Mean (SD) of pages per article & $106(31.8)$ \\
\hline Mean (SD) of pages per issue & $15(13)$ \\
\hline Paragraph or short text & $103(87)$ \\
\hline More than one page & $116(98)$ \\
\hline With illustrations & $4(3.8)$ \\
\hline Mean (SD) of illustrations per article & $92(78)$ \\
\hline Sources of information & $22(19)$ \\
\hline Health professional & $20(17)$ \\
\hline Governments, non-governmental organisations, World Health Organization & $12(10)$ \\
\hline No reference cited & $7(6)$ \\
\hline Medical journals & \\
\hline Hospitals, universities, research institutions & \\
\hline
\end{tabular}

Table 1 shows the main characteristics of these articles. Most were more than one page in size and included several illustrations. Almost all (111/118) were written exclusively by journalists, three were written by health professionals alone, one was written by a reader, and three had no authorship. Health professionals were indicated as the main sources of information in almost $80 \%$ of the articles, medical journals were mentioned as sources in $10 \%$ of the articles, and 17\% reported no specific source. We found 55 articles that presented the testimonials of women about their birthing experiences. These women reported 177 deliveries: 105 (59\%) reported vaginal deliveries, and $72(41 \%)$ reported caesarean sections. Most of these narratives had happy endings: $88 \%$ of deliveries by caesarean section and $98 \%$ of vaginal deliveries resulted in favourable maternal and perinatal outcomes (healthy mother and baby). More than half of the articles presented at least three medical facts on caesarean section, such as main maternal or fetal indications for caesarean section, details related to anaesthesia, and current rates of and statistics about caesarean section (table 2).

Figure 1 summarises the comprehensiveness of the information on potential benefits and risks of caesarean section provided in the articles. With regard to the benefits of caesarean section, although about 30\% of the articles did not mention any benefit, more than $43 \%$ mentioned three or more benefits. Short term maternal risks were more frequently reported than were long term maternal risks and perinatal risks. Whereas only about $18 \%(n=21)$ of the articles did not mention any short term maternal risks related to caesarean section, $66 \%$ of the articles did not mention any long term maternal risks $(\mathrm{n}=78)$ or perinatal risks $(\mathrm{n}=77)$.

Figure 2 compiles the information provided by magazines on the benefits and risks of caesarean section (detailed information provided in the web appendix). The main reported benefits of caesarean section (top right quadrant) were reduction of pain during delivery (mentioned by almost half of the articles), convenience for health professionals and family, and the possibility of choosing when to deliver (both mentioned by about $40 \%(n=48)$ of the articles). Prevention of urinary incontinence was reported in $9 \%(n=11)$ of the articles and preservation of sexual function and satisfaction in $7 \%(\mathrm{n}=8)$.

As figure 1 shows, more than $80 \%(n=97)$ of the articles mentioned at least one short term maternal risk or inconvenience related to caesarean section. Most focused mainly on the increased time needed for the mother to recover after a caesarean section $(n=48)$ and the fact that it is a less natural way of giving birth $(\mathrm{n}=47)$, which were each mentioned by approximately $40 \%$ of the articles. About $34 \%(n=40)$ of the articles pointed out the passive role of women or less control of the birth process as a negative characteristic of caesarean section. Less than $20 \%(\mathrm{n}=22)$ of the articles mentioned that delivery through caesarean section exposed the woman to increased risk of haemorrhage, 
Table 2 | Completeness of information on caesarean section transmitted in articles published in Brazilian women's magazines 1988-2008. Values are numbers (percentages)

\begin{tabular}{lc} 
Indicator & Articles (n=118) \\
Articles without any medical fact* on caesarean section & $11(9)$ \\
\hline Articles that mention 1-2 medical facts on caesarean section & $35(30)$ \\
\hline Articles that mention $\geq 3$ medical facts on caesarean section & $72(61)$ \\
\hline Specific scientific/objective information on caesarean section: & $62(53)$ \\
\hline Main maternal and fetal indications for caesarean section & $61(52)$ \\
\hline Need for/effects of anaesthesia for caesarean section & $55(47)$ \\
\hline Current caesarean section rates and statistics & $50(42)$ \\
\hline General maternal and perinatal risks of caesarean section & $37(31)$ \\
\hline WHO recommendations for caesarean section rate (15\%) & $22(19)$ \\
\hline Duration of hospital stay for caesarean section & $15(13)$ \\
\hline Medical costs for caesarean section and vaginal delivery
\end{tabular}

*Any objective, scientific information on caesarean section that can be found in recognised reliable source.

hysterectomy, or blood transfusions, and only $14 \%$ $(\mathrm{n}=16)$ mentioned increased risk of death. Less than $10 \%(n=8)$ mentioned the possibility of lesions to the bladder, ureters, or intestines, and approximately $2 \%$ $(\mathrm{n}=2)$ informed women that thromboembolism could occur as a consequence of caesarean section.

Less than a third of the articles provided information on long term maternal risks of caesarean section (bottom left quadrant of fig 2). The most frequently mentioned risks were increased possibility of repeat caesarean section and uterine rupture in future deliveries (reported by about $19 \%(\mathrm{n}=22)$ of articles). The possible occurrence of adhesions or chronic pains after repeated caesarean section was mentioned in 7\% $(n=8)$ of the articles, and increased risk of placenta praevia/accreta in $2.5 \%(\mathrm{n}=3)$.

Approximately two thirds of the articles did not provide any information on increased perinatal risks associated with caesarean section (upper left quadrant of fig 2). The most frequently mentioned perinatal risk associated with caesarean section was increased incidence of respiratory discomfort and iatrogenic prematurity (mentioned by approximately $20 \%(n=25)$ of the articles).

Table 3 shows the reasons why women would request a caesarean section. According to the 55 articles that mentioned reasons for wanting an elective antepartum caesarean section, the most frequently cited reason was "to avoid labour pain" followed by "family convenience." Eleven national celebrities described their experiences at giving birth to a total 13 infants (two women had two deliveries each): eight actresses, one singer, one basketball player, and the wife of an ex-president. Most (8/11) of these women had delivered vaginally and described the experience in positive terms. Three of the deliveries by caesarean section were considered positive by the celebrities and two were described in negative terms.

\section{DISCUSSION}

The information on caesarean section presented in Brazilian women's magazines was mostly balanced, not explicitly in favour of one or another route of delivery. However, overall, benefits of caesarean section were reported more frequently than were risks or inconveniences. Information provided on this route of delivery was not comprehensive in many aspects and did not provide important facts that could help readers to understand better the risks and benefits of delivering by caesarean section. For instance, less than $20 \%$ of the articles mentioned cost factors or the need for longer hospital stays for women having a caesarean section. Although more than $80 \%$ of the articles presented at least one short term risk or inconvenience associated with caesarean section, these were mostly related to social aspects or relatively innocuous outcomes, such as increased recovery time at home. Much more important risks related to caesarean section, such as infection, haemorrhage, or urinary or intestinal injuries, were completely ignored by more than $70 \%$ of the articles.

Even more troubling was the fact that only a third of the articles mentioned any long term maternal risks or perinatal complications potentially associated with caesarean section. For instance, only 22/118 articles stated that women with a previous caesarean section had an increased risk of uterine rupture in a future labour, only eight mentioned that repeated caesarean section could lead to adhesion or chronic pain, and only three mentioned the fact that a previous caesarean section could increase the risk of having placenta praevia or accreta in a future pregnancy. As these long term risks associated with caesarean section are well known to obstetricians, one may wonder if the omission of information on important risks associated with caesarean section was a deliberate editorial choice or the result of consulting poorly informed sources, such as non-specialist health professionals. Moyer et al also noticed the omission of the greatest morbidity and mortality risks faced by women in their analysis of health information provided to women through magazines in the United States. ${ }^{10}$ Moreover, incomplete discussion and omission of information have been detected in pregnancy related articles in magazines. ${ }^{22}$ Although caution needs to be exercised so as not to provoke unnecessary alarm, and some of these complications have a low incidence, they nevertheless could

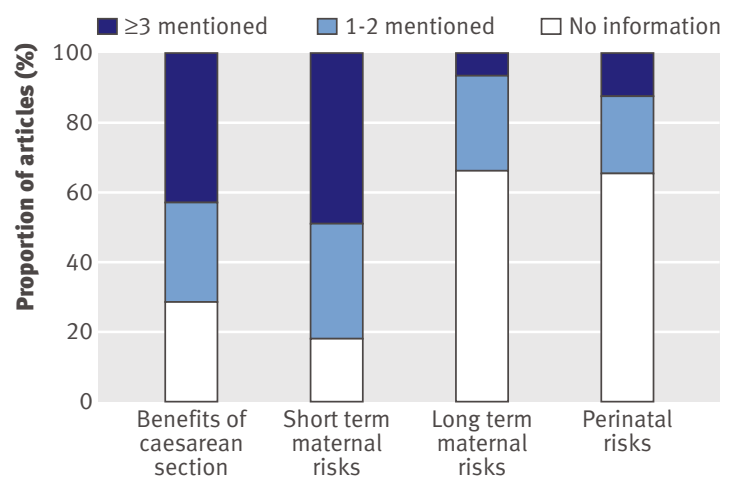

Fig 1| Information on caesarean section presented by 118 articles published in Brazilian women's magazines, 19882008 


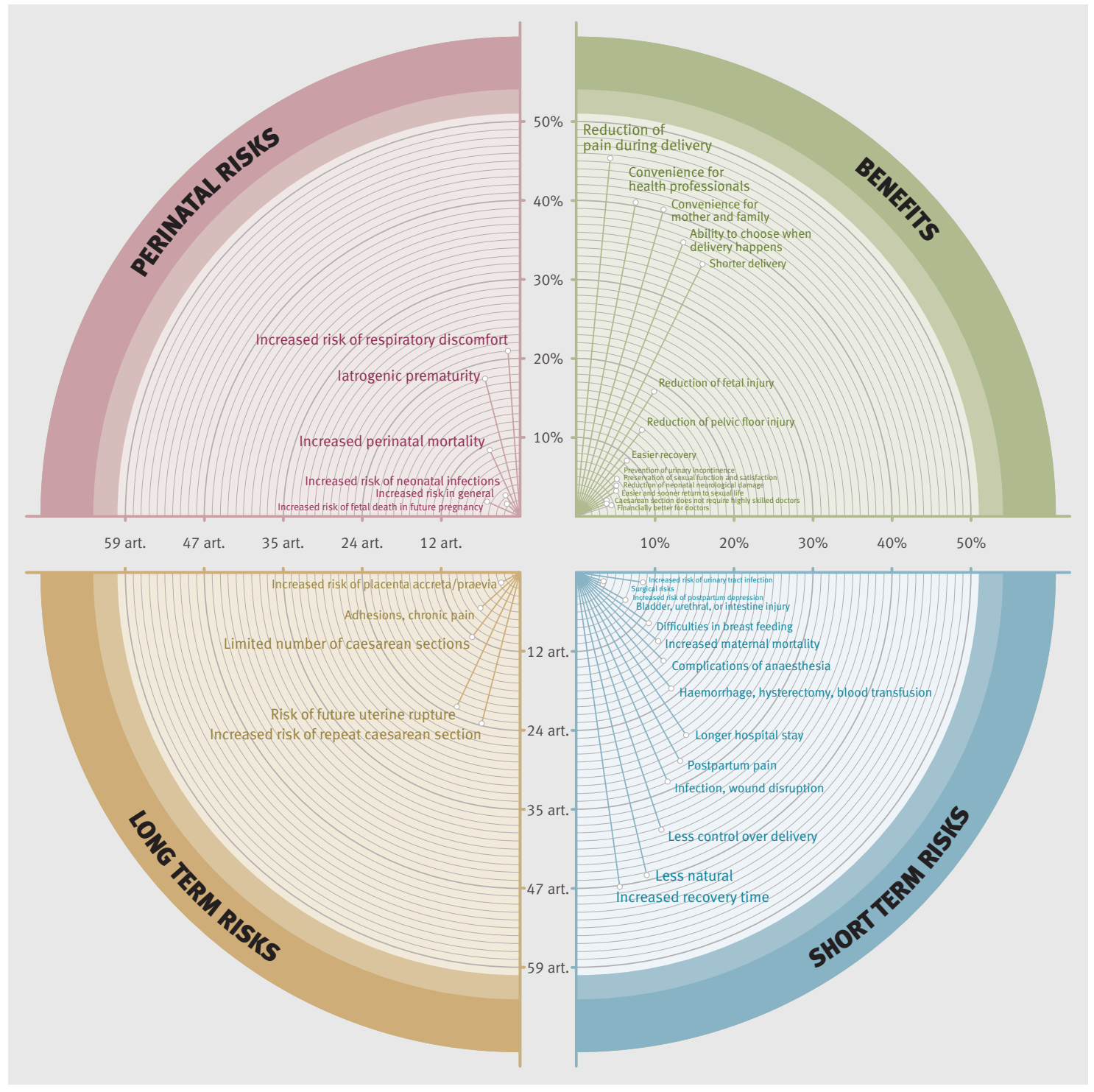

Fig 2 Information on benefits and risks of caesarean section transmitted to women by magazines in Brazil

have important implications and expose mother and child to serious complications that could lead to severe morbidity and mortality and expose doctors to processes of litigation.

Reduction of pain in labour was the most frequently reported benefit of caesarean section, mentioned by approximately $50 \%$ of the articles. Interestingly, a survey in Chile also reported that this is the main reason cited by women for wanting a caesarean section. ${ }^{23}$ These findings suggest that increased availability of analgesia/anaesthesia and other methods to reduce pain in vaginal delivery could hypothetically reduce the number of caesarean sections done because of maternal fear of labour pain.

Medical practitioners were the only source of information in the vast majority of the articles. Although most of the physicians cited by the authors were specialists (obstetricians and gynaecologists), this does not necessarily imply expertise or lack of bias/subjectivity on the route of delivery. Very few articles cited universities, specialised hospitals, international organisations, or research institutions as their source of information, and only $10 \%$ reported that information came from medical journals. Equally troubling is the fact that $17 \%$ of the articles did not mention any source for the information presented. The use of suboptimal sources of information can in part explain the lack of accuracy, reliability, and completeness of the information on caesarean section presented by most of the articles published in these magazines. As most lay women cannot critically appraise what they are reading, this can have serious consequences. The lack of information about medical sources of information in many of these articles contrasts markedly with the easily available contact information of where to find, order, or purchase clothes, accessories, or decorative items presented in other articles printed in the same issues of these women's magazines.

Although several celebrities reported positive personal experiences of vaginal deliveries, the rate of 
Table $3 \mid$ Reasons why women would request elective (without medical indication) caesarean section according to Brazilian women's magazines, 1988-2008. Values are numbers (percentages)

Articles $(n=118)$

Reasons for antepartum elective caesarean section

\begin{tabular}{lc}
\hline No reasons mentioned & $63(53)$ \\
\hline Articles that give reasons for elective caesarean section: & $55(47)$ \\
\hline To avoid labour pain & $37(31)$ \\
\hline For convenience of family & $20(17)$ \\
\hline Fear of vaginal delivery & $11(9)$ \\
\hline To avoid surprises and rushing; to control things & $7(6)$ \\
\hline For medical convenience & $4(3)$ \\
\hline Reasons for intrapartum elective caesarean section & $111(94)$ \\
\hline No reason mentioned & $7(6)$ \\
\hline Reason: pain, fatigue, despair
\end{tabular}

caesarean section among these role models was almost $40 \%(5 / 13)$. However, the low number of articles of this type (only 11/118) did not allow more detailed analyses of these testimonials.

\section{Strengths and limitations}

A strong point of this study is its uniqueness. Although previous publications have analysed the influence of the media on osteoporosis, contraception, diet, exercise, and general women's health matters, ${ }^{1022425}$ to the best of our knowledge, this is the first publication to specifically analyse how caesarean section is portrayed by women's magazines. Before starting this study, we did a literature review of papers available through Medline (1967-2007) on the media portrayal of caesarean section; the lack of publications on this specific area led us to pursue this study and analysis.

Limitations of this review are related to the difficulty of objectively evaluating health reports directed to the lay public and the lack of uniform, comprehensive, and internationally accepted standards and assessment tools to critically appraise this type of literature. We tried to minimise subjectivity and bias by using a very structured data extraction form created on the basis of criteria presented by Oxman et al to assess health reports in the lay press, ${ }^{17}$ in addition to double data extraction and discussion of a considerable proportion of all articles. However, we acknowledge the fact that some degree of subjectivity in assessing the scientific quality of health related articles in the press is inevitable. We also acknowledge the fact that although our review looks back at what has been published in the past 20 years, the current rate of caesarean section would more likely reflect current portrayal in magazines. However, as our objective was not to compare the trends in rising caesarean section rates in Brazil over time with the contents of articles on caesarean section published in women's magazines, we did not compare these two types of data. Undoubtedly, the increasing rates of caesarean section in Brazil over the past decades are the result of multiple factors. Therefore, we believe that any attempt to hypothesise a direct causal relation between what is published in women's magazines in any given year or period and the rate of caesarean section during the same period would be simplistic and unrealistic.

This study could not and did not intend to evaluate the effect of Brazilian women's magazines in shaping their readers' opinion or whether they actually influenced women's decisions on caesarean section or vaginal delivery. Furthermore, we acknowledge that women's magazine articles are not the only source of information that could influence the opinion of women on route of delivery. Much has been written about the portrayal of birth and other health related matters on various popular media such as free to air television, pay television, and the internet. However, in a recent Australian survey, 200 obstetricians ranked women's magazines as the most important media to influence their patients' attitudes to caesarean section and current rates, ahead of websites, newspaper articles, and television. ${ }^{9}$

\section{Implications}

Although it is difficult to measure, the mass media clearly influence individual behaviours, healthcare use, healthcare practices, and health policy. ${ }^{1725}$ Women's magazines represent an important source of information on pregnancy and childbirth, ${ }^{9-11}$ this being one of the topics that receive the most requests for information from female readers. ${ }^{10}$ In this context, women's magazines can play an important role in disseminating this type of information, offering behavioural directives, and suggesting actions to take.

Considering the unprecedented worldwide increase in the rate of caesarean section, improving the scientific quality of the information reported on this topic should be an important goal for women's magazines, engaging as partners in this global public health challenge. The editors of Brazilian women's magazines should encourage their reporters, journalists, and writers to seek good sources of evidence to ensure that, in the future, the information on caesarean section presented in their issues is accurate and complete.

This review of magazines in Brazil is part of a larger worldwide multi-country investigation covering women's magazines from countries in Europe, Latin America, and North America, where rates of caesarean section are increasing in an unprecedented manner. The aims of this investigation are to contribute to a better understanding of what type of information women are getting from magazines on options for childbirth. We hope the results from this investigation will increase awareness and set the basis for improved reporting.

\section{Conclusion}

Most of the articles on caesarean section published over the past two decades in Brazilian women's magazines have not used good sources of information. The portrayal of caesarean section is incomplete and may be leading women to underestimate important maternal and perinatal risks associated with this route of delivery. 


\section{WHAT IS ALREADY KNOWN ON THIS TOPIC}

Caesarean section rates are increasing worldwide, but despite worldwide concern, debate, and research, the modifiable causes of this increase remain unclear

Women's magazines are one of the most ubiquitous sources of information and can play a critical role in shaping women's opinions and influencing their decisions on childbirth options

\section{WHAT THIS STUDY ADDS}

The portrayal of caesarean section in women's magazines in Brazil is incomplete and may be leading women to underestimate important maternal and perinatal risks associated with this route of delivery

According to Brazilian women's magazines, avoidance of labour pain and convenience for the family are the two main reasons for women to want a caesarean section

Most of the articles on caesarean section published over the past two decades in Brazilian women's magazines have not used good sources of information

Contributors: MRT and APB participated in the conception and design of the study; acquired, analysed, and interpreted data; drafted the manuscript; and contributed with administrative and technical support. SD acquired, analysed, and interpreted data; contributed with administrative and technical support; and provided critical revision of the manuscript for important intellectual content. MW and JPS participated in the conception and design of the study, analysis and interpretation of data, and critical revision of the manuscript for important intellectual content analyses. MM participated in the conception and design of the study and critical revision of the manuscript and provided technical and administrative support. MRT and APB are the guarantors.

Funding: World Health Organization.

Competing interests: All authors have completed the Unified Competing Interest form at www.icmje.org/coi_disclosure.pdf (available on request from the corresponding author) and declare: no support from any organisation for the submitted work; no financial relationships with any organisations that might have an interest in the submitted work in the previous three years; no other relationships or activities that could appear to have influenced the submitted work.

Ethical approval: Not needed.

Data sharing: No additional data available.

1 Althabe F, Sosa C, Belizan JM, Gibbons L, Jacquerioz F, Bergel E. Cesarean section rates and maternal and neonatal mortality in lowmedium-, and high-income countries: an ecological study. Birth 2006;33:270-7.

2 Belizan JM, Althabe F, Barros FC, Alexander S. Rates and implications of caesarean sections in Latin America: ecological study. BMJ 1999;319:1397-400

3 Belizan JM, Cafferata ML, Althabe F, Buekens P. Risks of patient choice cesarean. Birth 2006;33:167-9.

4 Lumbiganon P, Laopaiboon M, Gulmezoglu AM, Souza JP, Taneepanichskul S, Ruyan P, et al. Method of delivery and pregnancy outcomes in Asia: the WHO global survey on maternal and perinatal health 2007-08. Lancet 2010;375:490-9.

5 Villar J, Valladares E, Wojdyla D, Zavaleta N, Carroli G, Velazco A, et al. Caesarean delivery rates and pregnancy outcomes: the 2005 WHO global survey on maternal and perinatal health in Latin America. Lancet 2006;367:1819-29.

6 Betran AP, Merialdi M, Lauer JA, Bing-Shun W, Thomas J, Van LP, et al. Rates of caesarean section: analysis of global, regional and national estimates. Paediatr Perinat Epidemiol 2007;21:98-113.

7 Brazilian Ministry of Health. Pesquisa Nacional de Demografía e Saúde da Criança e da Mulher. 2008. www.saude.gov.br/pnds2006.

8 Hopkins K. Are Brazilian women really choosing to deliver by cesarean? Soc Sci Med 2000;51:725-40.

9 Handfield B, Turnbull S, Bell RJ. What do obstetricians think about media influences on their patients? Aust N Z J Obstet Gynaecol 2006;46:379-83.

10 Moyer CA, Vishnu LO, Sonnad SS. Providing health information to women: the role of magazines. Int J Technol Assess Health Care 2001;17:137-45.

11 Usha Kiran TS, Jayawickrama NS. Who is responsible for the rising caesarean section rate? J Obstet Gynaecol 2002;22:363-5.

12 Fuglenes D, Oian P, Kristiansen IS. Obstetricians' choice of cesarean delivery in ambiguous cases: is it influenced by risk attitude or fear of complaints and litigation? Am J Obstet Gynecol 2009;200:48.

13 Kalish RB, McCullough L, Gupta M, Thaler HT, Chervenak FA. Intrapartum elective cesarean delivery: a previously unrecognized clinical entity. Obstet Gynecol 2004;103:1137-41.

14 Grupo de Midia São Paulo. Midia Dados Brasil. 2010. www.gm.org. $\mathrm{br} /$ page/midia-dados.

15 Circulation Verifying Institute. Instituto Verificador de CirculaçãoIVC. 2008. www.ivc.org.br/.

16 National Association of Magazine Editors. Associação Nacional de Editores de Revistas. 2008. www.aner.org.br/.

17 Oxman AD, Guyatt GH, Cook DJ, Jaeschke R, Heddle N, Keller J. An index of scientific quality for health reports in the lay press. / Clin Epidemiol 1993;46:987-1001.

18 National Institutes of Health. State-of-the-science conference statement on cesarean delivery on maternal request. AHRQ Publications Clearinghouse, 2006.

19 American College of Obstetricians and Gynecologists. Committee opinion No 394, December 2007: cesarean delivery on maternal request. Obstet Gynecol 2007;110:1501.

20 National Institute for Clinical Excellence. Caesarean section. NICE, 2004. (Clinical guideline 13.)

21 American College of Obstetricians and Gynecologists Task Force on Cesarean Delivery Rates. Evaluation of cesarean delivery. ACOG, 2000.

22 Gunderson SA. Critical review of articles regarding pregnancy exposures in popular magazines. Annual Meeting of the Teratology Societies, 1986.

23 Angeja AC, Washington AE, Vargas JE, Gomez R, Rojas I, Caughey AB. Chilean women's preferences regarding mode of delivery: which do they prefer and why? BJOG 2006;113:1253-8.

24 Wallace LS, Ballard JE. Osteoporosis coverage in selected women's magazines and newspapers, 1998-2001. Am J Health Behav 2003;27:75-83.

25 Weston LC, Ruggiero JA. The popular approach to women's health issues: a content analysis of women's magazines in the 1970s. Women Health 1985:10:47-62.

Accepted: 29 October 2010 